\title{
Electrical transport in magnesium aluminate
}

\author{
TOM MATHEWS, K T JACOB* and J P HAJRA \\ Department of Metallurgy, Indian Institute of Science, Bangalore 560012, India \\ MS received 12 March 1990; revised 3 May 1990
}

\begin{abstract}
The conductivity of $\mathrm{MgAl}_{2} \mathrm{O}_{4}$ has been measured at 1273,1473 and $1673 \mathrm{~K}$ as a function of the partial pressure of oxygen ranging from $10^{5}$ to $10^{-14} \mathrm{~Pa}^{1}$. The $\mathrm{MgAl}_{2} \mathrm{O}_{4}$ pellet, sandwiched between two platinum electrodes, was equilibrated with a flowing stream of either $\mathrm{Ar}+\mathrm{O}_{2}, \mathrm{CO}+\mathrm{CO}_{2}$ or $\mathrm{Ar}+\mathrm{H}_{2}+\mathrm{H}_{2} \mathrm{O}$ mixture of known composition. The gas mixture established a known oxygen partial pressure. All measurements were made at a frequency of $1 \mathrm{kHz}$. These measurements indicate pressure independent ionic conductivity in the range 1 to $10^{-14} \mathrm{~Pa}$ at $1273 \mathrm{~K}, 10^{-1}$ to $10^{-12} \mathrm{~Pa}$ at $1473 \mathrm{~K}$ and $10^{-1}$ to $10^{-4} \mathrm{~Pa}$ at $1673 \mathrm{~K}$. The activation energy for ionic conduction is $1.48 \mathrm{eV}$, close to that for self-diffusion of $\mathrm{Mg}^{2+}$ ion in $\mathrm{MgAl}_{2} \mathrm{O}_{4}$ calculated from the theoretical relation of Glyde. Using the model, the energy for cation vacancy formation and activation energy for migration are estimated.
\end{abstract}

Keywords. $\mathrm{MgAl}_{2} \mathrm{O}_{4}$; spinel; electrical conductivity; conductivity mechanism; ionic transport.

\section{Introduction}

Magnesium aluminate is a normal spinel at low temperature. The unit cell consists of 32 oxygen ions in an approximately face-centred cubic arrangement with the divalent magnesium ions occupying 8 of the 64 tetrahedral interstices and the trivalent aluminium ions occupying 16 out of the 32 octahedral interstices. To explore the possible use of $\mathrm{MgAl}_{2} \mathrm{O}_{4}$ as a solid electrolyte at elevated temperatures, its electrical conductivity has been measured as a function of temperature and oxygen partial pressure. The ionic conductivity in oxides with narrow homogeneity ranges is expected to be independent of oxygen partial pressure. The hole conductivity generally increases with oxygen partial pressure $\left(\sigma_{h} \alpha P_{\mathbf{O}_{2}}^{1 / n}\right)$. The electronic conductivity increases with decreasing partial pressure $\left(\sigma_{e} \alpha P_{\mathbf{O}_{2}}^{-1 / n}\right)$. Thus measurement of the total conductivity as a function of oxygen partial pressure gives an indication of the ionic conduction domain in the temperature - oxygen partial pressure plot. Recently Metselaar and Hoefsloot (1987) have reported on the electrical transport properties of calcium and barium aluminates.

\section{Experimental}

The conductivity of $\mathrm{MgAl}_{2} \mathrm{O}_{4}$ was measured at different temperatures as a function of oxygen partial pressure. $\mathrm{MgAl}_{2} \mathrm{O}_{4}$ pellets, sandwiched between two platinum electrodes, were equilibrated at different temperatures with flowing streams of $\mathrm{Ar}+\mathrm{O}_{2}$, $\mathrm{CO}+\mathrm{CO}_{2}$ and $\mathrm{Ar}+\mathrm{H}_{2}+\mathrm{H}_{2} \mathrm{O}$ mixtures of known compositions. The gas phase

\footnotetext{
${ }^{*}$ For correspondence.
} 
established a partial pressure of oxygen over the electrodes depending on its composition. Mixtures of $\mathrm{Ar}+\mathrm{O}_{2}$ allow the control of oxygen partial pressure $\left(P_{\mathrm{O}_{2}} / P^{\circ}\right)$ up to $10^{-4} \mathrm{~Pa}$, where $P^{0}$ in the standard pressure $\left(1.01 \times 10^{5} \mathrm{~Pa}\right)$. For the $\mathrm{CO}+\mathrm{CO}_{2}$ mixture, the oxygen partial pressure is defined by the relations

$$
\begin{aligned}
2 \mathrm{CO} & +\mathrm{O}_{2} \rightleftarrows 2 \mathrm{CO}_{2}, \\
P_{\mathrm{O}_{2}} & =\left(P_{\mathrm{CO}_{2}} / P_{\mathrm{CO}}\right)^{2} K_{1}^{-1} \\
& =\left(P_{\mathrm{CO}_{2}} / P_{\mathrm{CO}}\right)^{2} \exp \left(\Delta G_{1}^{0} / R T\right),
\end{aligned}
$$

where $K_{1}$ and $\Delta G_{1}^{0}$ are the equilibrium constant and standard Gibbs' free energy change for reaction (1). Similarly, for $\mathrm{Ar}+\mathrm{H}_{2}+\mathrm{H}_{2} \mathrm{O}$ mixtures the oxygen partial pressure is defined by

$$
\begin{aligned}
& 2 \mathrm{H}_{2}+\mathrm{O}_{2} \rightleftarrows 2 \mathrm{H}_{2} \mathrm{O}, \\
& P_{\mathrm{O}_{2}}=\left(P_{\mathrm{H}_{2} \mathrm{O}} / P_{\mathrm{H}_{2}}\right)^{2} \quad K_{3}^{-1}=\left(P_{\mathrm{H}_{2} \mathrm{O}} / P_{\mathrm{H}_{2}}\right)^{2} \exp \left(\Delta G_{3}^{0} / R T\right) .
\end{aligned}
$$

Argon is added to the mixture of hydrogen and water vapour to minimize thermal segregation in the gas phase. The conductivity of the sample was measured at a frequency of $1 \mathrm{kHz}$.

\subsection{Materials}

Fine powders of $\mathrm{MgO}$ and $\alpha-\mathrm{Al}_{2} \mathrm{O}_{3}, 99.99 \%$ pure, were obtained from the Aldrich. $\mathrm{MgAl}_{2} \mathrm{O}_{4}$ was prepared by heating stoichiometric amounts of component oxides at $1473 \mathrm{~K}$ for $168 \mathrm{~h}$. The pellets made from intimate mixtures of component oxides were contained in a recrystallized high density alumina crucible. The saturation of $\mathrm{MgAl}_{2} \mathrm{O}_{4}$ with $\alpha-\mathrm{Al}_{2} \mathrm{O}_{3}$ at $1473 \mathrm{~K}$ was limited only to the contact surface. The surface of the pellet was polished to remove the layer of $\mathrm{MgAl}_{2} \mathrm{O}_{4}$ saturated with $\alpha-\mathrm{Al}_{2} \mathrm{O}_{3}$. The formation of $\mathrm{MgAl}_{2} \mathrm{O}_{4}$ spinel was confirmed by X-ray diffraction analysis (XRD). The sample contained single phase $\mathrm{MgAl}_{2} \mathrm{O}_{4}$, free from the starting oxides within the detection limit of XRD. The platinum electrodes on the two flat surfaces of the $\mathrm{MgAl}_{2} \mathrm{O}_{4}$ pellet were prepared by painting with a brush Engelhardt platinum paste No. T. 11500 . The electrodes were heated in air for $0.5 \mathrm{~h}$ at $1073 \mathrm{~K}$, and then heated in vacuum at $1000 \mathrm{~K}$ for $0.5 \mathrm{~h}$. Argon gas (99.99\% pure) was dried and then passed through copper turnings maintained at $800 \mathrm{~K}$ to remove residual oxygen. Hydrogen gas $(99.99 \%$ pure) was passed over a catalyst to convert residual oxygen to water vapour, which was then absorbed in a drying column. $\mathrm{CO}_{2}$ gas $(99.99 \%$ pure), obtained from a commercial source, was dried before use.

\subsection{Apparatus}

A schematic representation of the cell used for the conductivity measurement is shown in figure 1. A cylindrical pellet of $\mathrm{MgAl}_{2} \mathrm{O}_{4}, 0.5 \mathrm{~cm}$ thick and coated on either side with platinum, was sandwiched between two platinum foils. The $\mathrm{MgAl}_{2} \mathrm{O}_{4}$ pellet was prepared by double end compression of fine powder and subsequent sintering in air at $1873 \mathrm{~K}$. The density of the pellet was $96 \%$ of the theoretical value. The flat surfaces were polished before coating with platinum paste. The sandwich was pressed between 


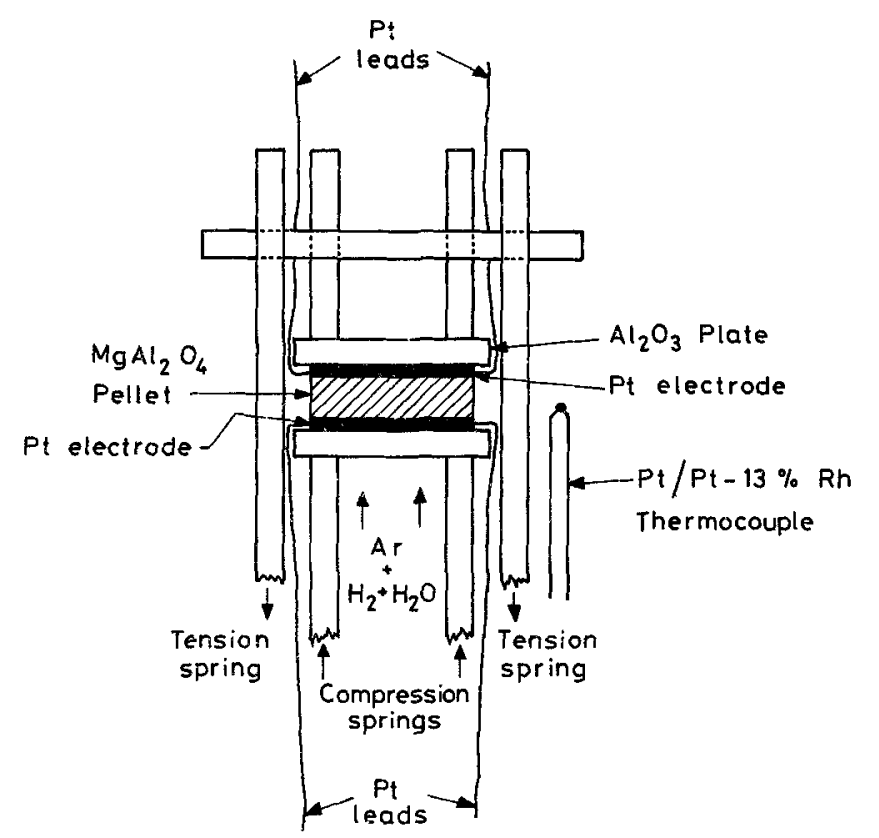

Figure 1. Schematic diagram of the conductivity cell.

alumina discs. The assembly was spring-loaded using a system of alumina slabs and tubes. The cell assembly was housed inside a vertical alumina tube fitted on each end with brass heads having provision for gas inlet and outlet and insulated electrical and thermocouple leads. The gas mixture was passed through the tube at a rate of $4 \mathrm{ml} \mathrm{s}^{-1}$ in case of $\mathrm{Ar}+\mathrm{O}_{2}$ and $\mathrm{CO}+\mathrm{CO}_{2}$ mixtures. The $\mathrm{Ar}+\mathrm{H}_{2}+\mathrm{H}_{2} \mathrm{O}$ mixture was flown at a linear velocity of $2 \mathrm{~cm} \mathrm{~s}^{-1}$. It has been shown earlier that there is negligible thermal segregation in $\mathrm{Ar}+\mathrm{H}_{2}+\mathrm{H}_{2} \mathrm{O}$ gas mixtures at this flow rate (Darken and Gurry 1945). The gas mixture established an oxygen partial pressure over the $\mathrm{Pt}\left|\mathrm{MgAl}_{2} \mathrm{O}_{4}\right| \mathrm{Pt}$ sandwich. The temperature of the sample was measured by a $\mathrm{Pt} \mid \mathrm{Pt}-13 \% \mathrm{Rh}$ thermocouple placed adjacent to it. The entire assembly was suspended in a vertical molybdenum resistance furnace with an even temperature zone of $3 \mathrm{~cm}$ in which the sample was placed. The temperature of the furnace was controlled to $\pm 1 \mathrm{~K}$. Thick platinum leads were used to make electrical contact with the sample pellet. Twin leads were used for each electrode. One set of leads was connected to an impedance bridge and the other set was connected to a high impedance voltmeter.

A schematic sketch of the apparatus for preparing the $\mathrm{Ar}+\mathrm{H}_{2}+\mathrm{H}_{2} \mathrm{O}$ gas mixture is given in figure 2 . One stream of prepurified argon was passed through a copper coil and then bubbled through a series of conical flasks containing either water or sulphuric acid-water mixtures of known composition and density. The copper coil and flasks were kept in a circulating water thermostat, the temperature of which was controlled to $\pm 0.1 \mathrm{~K}$. The copper tube allowed the gas to be heated rapidly to the temperature of the water bath. The $\mathrm{H}_{2} \mathrm{SO}_{4}-\mathrm{H}_{2} \mathrm{O}$ mixture, maintained at constant temperature, established a known partial pressure of $\mathrm{H}_{2} \mathrm{O}$ in the argon gas (Hodgman 1963). The flow rate of the argon gas passing through the water saturator was accurately set by a mass flow controller. The controlled stream of $\mathrm{Ar}+\mathrm{H}_{2} \mathrm{O}$ was mixed with another accurately controlled stream of $\mathrm{H}_{2}$ and additional argon in a gas mixer. $\mathrm{The}_{2} \mathrm{H}_{2} / \mathrm{H}_{2} \mathrm{O}$ ratio of the 


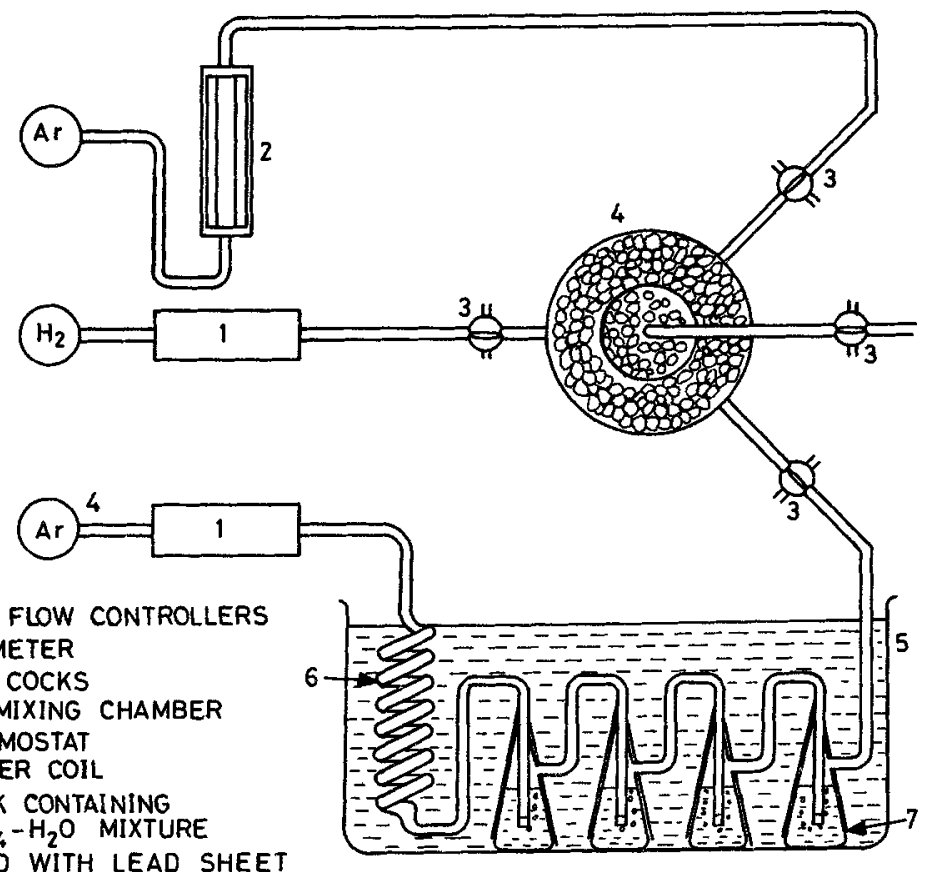

1. MASS FLOW CONTROLLERS

2. ROTAMETER

3. STOP COCKS

4. GAS MIXING CHAMBER

5. THERMOSTAT

6. COPPER COIL

7. FLASK CONTAINING $\mathrm{H}_{2} \mathrm{SO}_{4}-\mathrm{H}_{2} \mathrm{O}$ MIXTURE LINED WITH LEAD SHEET

Figure 2. Schematic diagram of the apparatus for the preparation of $\mathrm{Ar}+\mathrm{H}_{2}+\mathrm{H}_{2} \mathrm{O}$ gas mixtures.

gas mixture was calculated from the flow rates of the hydrogen and argon gas streams as well as by the temperature and composition of the sulphuric acid-water mixture in the thermostat. The argon concentration in the mixture was always greater than $60 \%$. This method allows the preparation of mixtures with $\boldsymbol{P}_{\mathrm{H}_{2}} / \boldsymbol{P}_{\mathrm{H}_{2} \mathrm{O}}$ ratios ranging from 1000 to 15 . At higher concentrations of water vapour in the gas stream, condensation occurs in the cold regions of the gas train. The $\mathrm{CO}+\mathrm{CO}_{2}$ mixture was prepared in situ. $\mathrm{CO}_{2}$ was initially admitted into a closed system linking two furnaces and a gas circulation pump. One furnace contained the sample and another Kanthal furnace contained a condensed redox mixture. Mixtures of $\mathrm{Cu}+\mathrm{Cu}_{2} \mathrm{O}, \mathrm{Ni}+\mathrm{NiO}, \mathrm{Co}+\mathrm{CoO}$ or $\mathrm{Fe}+$ ' $\mathrm{FeO}$ ' were used in the Kanthal furnace. The temperature of the Kanthal furnace determines the $\mathrm{CO} / \mathrm{CO}_{2}$ ratio over the redox couple. Different gas ratios can be obtained by varying either the temperature of the couple or by using different couples. At $\boldsymbol{P}_{\mathrm{CO}} / P_{\mathrm{CO}_{2}}$ ratios greater than 5 , carbon deposition was noticed along the alumina tube where the temperature ranges from $950-1050 \mathrm{~K}$. The gas was pumped through the closed system at a rate of about $4 \mathrm{ml} \mathrm{s}^{-1}$. The gas phase, whose composition is controlled by the redox couple and its temperature, is circulated over the $\mathrm{MgAl}_{2} \mathrm{O}_{4}$ sample.

\section{Results}

The conductivity is plotted as a function of oxygen partial pressure at various temperatures in figure 3. The conductivity is almost independent of oxygen partial 


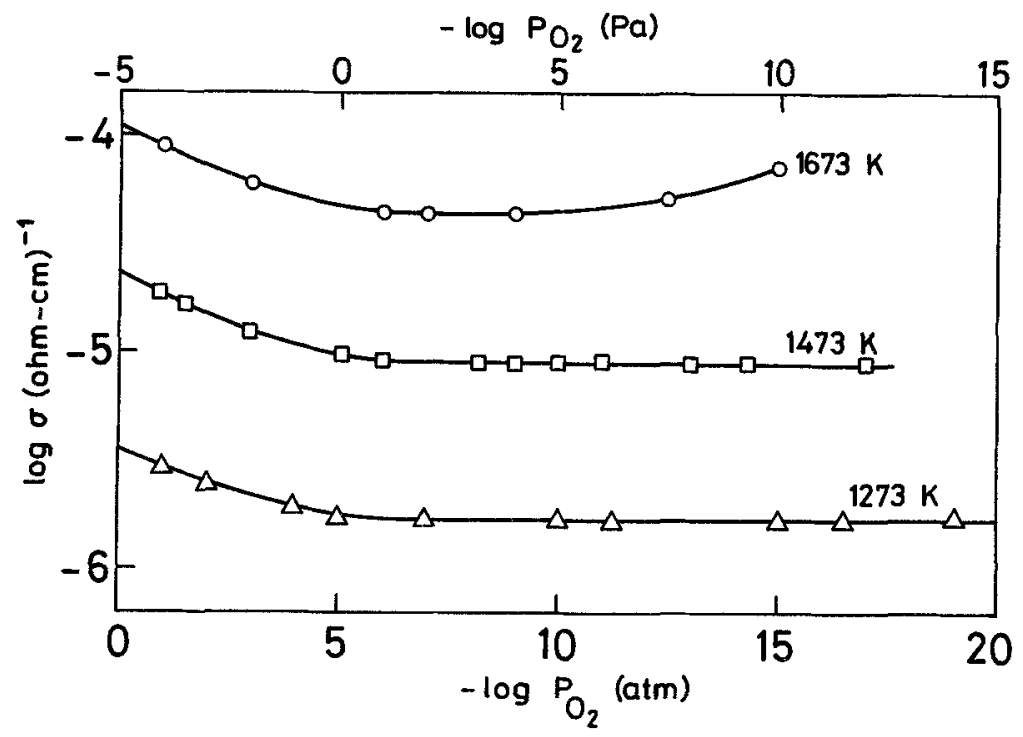

Figure 3. Conductivity versus oxygen partial pressure.

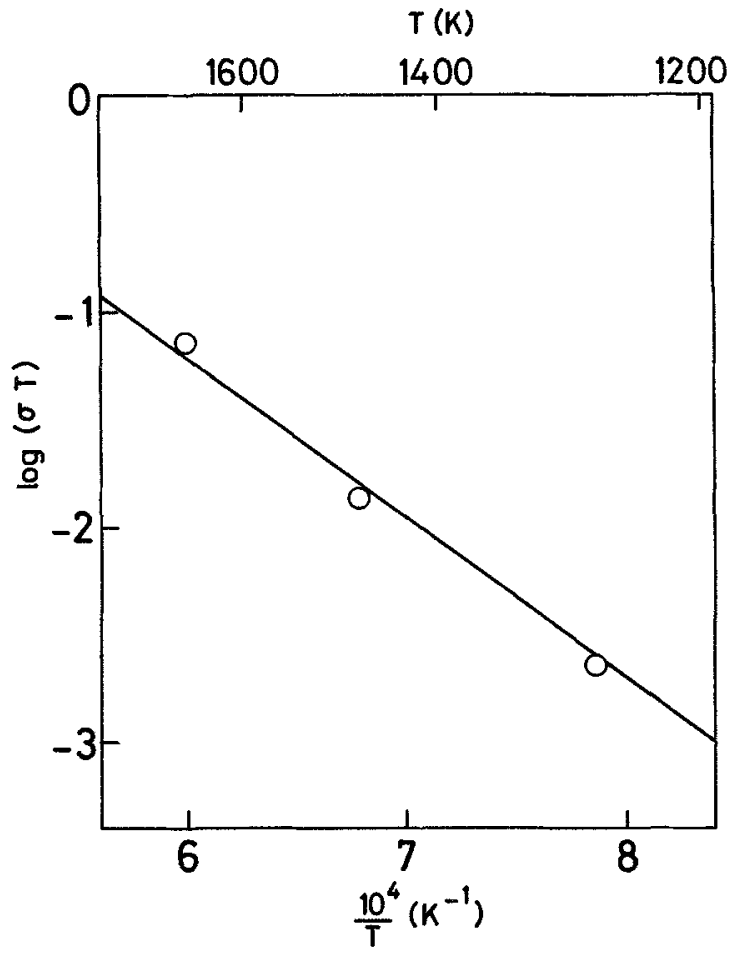

Figure 4. Variation of pressure independent conductivity with the reciprocal of absolute temperature. 
pressure in the range 1 to $10^{-14} \mathrm{~Pa}$ at $1273 \mathrm{~K}, 10^{-1}$ to $10^{-12} \mathrm{~Pa}$ at $1473 \mathrm{~K}$ and $10^{-1}$ to $10^{-4} \mathrm{~Pa}$ at $1673 \mathrm{~K}$. In this range, ions are the probable charge carriers. The conductivity increases at higher oxygen pressures signaling the onset of hole conduction. At $1673 \mathrm{~K}$ increase in conductivity is also seen at oxygen partial pressures below $10^{-4} \mathrm{~Pa}$. This is probably due to the onset of electronic conduction. The low oxygen partial pressure limit for onset of electronic conduction was not found at 1273 and $1473 \mathrm{~K}$ within the range of pressures investigated in this study. The results indicate that $\mathrm{MgAl}_{2} \mathrm{O}_{4}$ is an ionic conductor over a restricted range of oxygen partial pressures. The ionic conduction domain narrows rapidly with increasing temperature. It would be interesting to determine the ionic transport number to confirm the conclusions derived from the conductivity study. The variation of the logarithm of ionic conductivity with the reciprocal of absolute temperature is shown in figure 4 . The activation energy for ionic conduction is $1.49( \pm 0.08) \mathrm{eV}$.

\section{Discussion}

For face-centred cubic metals the activation energy $(Q)$ for self-diffusion can be related to the Debye temperature, $\theta_{\mathrm{D}}$, of the metal by the following expression (Glyde 1967)

$$
Q=2.21 \times 10^{-2}(k / h)^{2} \mathrm{~m} \theta_{\mathrm{D}}^{2} \mathrm{~d}^{2},
$$

where $k$ is the Boltzmann constant, $\hbar$ the Planck's constant divided by $2 \pi, m$ the mass of the diffusing species in atomic mass units, and $d$ the jump distance in $\AA$. The Debye temperature appearing in (5) corresponds to the frequency spectrum averages appearing in the Debye-Waller (D-W) factor rather than to the value derived from specific heat. The value of $\theta_{\mathrm{D}}(\mathrm{D}-\mathrm{W})$ is usually about $5 \%$ greater than the value of $\theta_{\mathrm{D}}\left(C_{v}\right)$.

Self-diffusion in spinels is more complex because of the variety of diffusing species within a given compound and also because of the possibility of different routes for migration. However, cubic spinels have a structure with an approximate close packing of oxygen ions and metal ions occupying tetrahedral and octahedral interstices. Thus there are close structural resemblances to the face-centred cubic metals. Hence it is assumed that the numerical factor $2.21 \times 10^{-2}$, deduced by Glyde (1967) for the facecentred cubic metals, is also appropriate for cubic spinels and as a result (5) holds good in the case of spinels too.

$\mathrm{MgAl}_{2} \mathrm{O}_{4}$ is a normal spinel at low temperature. Although some amount of cation disorder would be encountered at high temperatures because of the exchange of $\mathrm{Mg}^{2+}$ and $\mathrm{Al}^{3+}$ ions between the tetrahedral and octahedral sites, the major fraction of the $\mathrm{Mg}^{2+}$ ions would be located at the tetrahedral site. In normal spinels the divalent cation is generally found to be more mobile than the trivalent cation (Schmalzried 1974). In spinels each tetrahedral site is surrounded by 6 nearest similar sites $a / 4$ away and 4 nearest octahedral sites $a \sqrt{3} / 8$ away, all of which are unoccupied. $a$ represents the lattice parameter. In this case the diffusing ion can migrate via a tetrahedral site only or can migrate to a vacant octahedral site followed by migration to a vacant tetrahedral site. With close packing of oxygen ions the latter should be the preferred route since migration through tetrahedral sites alone involves separating two neigh- 
bouring oxygen ions. Assuming that the diffusing $\mathrm{Mg}^{2+}$ ions initially occupying the tetrahedral voids in the $\mathrm{MgAl}_{2} \mathrm{O}_{4}$ spinel migrate from a tetrahedral to a vacant octahedral site followed by migration to a vacant tetrahedral site, and using the values of $\theta_{\mathrm{D}}(\mathrm{D}-\mathrm{W})=700 \mathrm{~K}$ for $\mathrm{MgAl}_{2} \mathrm{O}_{4}$ obtained from neutron diffraction (Bacon 1952) and the lattice parameter $a=8.08 \AA$, one obtains an activation energy $1.45 \mathrm{eV}$ for the self-diffusion of $\mathrm{Mg}^{2+}$ ions which is close to the experimental value of $1.49 \mathrm{eV}$. If the $\mathrm{Mg}^{2+}$ ions were to migrate via tetrahedral sites only then the calculated activation energy for self-diffusion would be $1.94 \mathrm{eV}$.

In the spinel structure each octahedral site is surrounded by 12 nearest sites of similar nature at a distance $a \sqrt{2} / 4$. Of these 6 would normally be occupied. Each occupied octahedral site is also surrounded by 8 tetrahedral sites at a distance of $a \sqrt{3} / 8$. All these tetrahedral sites are not occupied. If the $\mathrm{Al}^{3+}$ ion in $\mathrm{MgAl}_{2} \mathrm{O}_{4}$ were to migrate only via octahedral sites, the activation energy would be $4 \cdot 31 \mathrm{eV}$. If the $\mathrm{Al}^{3+}$ ion were to migrate to a neighbouring tetrahedral site and then on to a vacant octahedral site, the activation energy would be $1.62 \mathrm{eV}$.

The packing of oxygen is not perfect in the spinel structure. If the packing is perfect the oxygen parameter $u$ would have a value of 0.325 . In $\mathrm{MgAl}_{2} \mathrm{O}_{4} u=0 \cdot 387$. Although in the case of perfect packing each oxygen site is surrounded by 12 others at a distance of $a / 2 \sqrt{2}$, in actual spinels each oxygen has three types of neighbouring oxygen sites: (i) six neighbours at a distance of $a\left(1+32 \delta^{2}\right)^{\frac{1}{2}} / 2 \sqrt{2}$ forming a plane parallel to 111 where $\delta=u-0.375$; (ii) three neighbours at a distance $a(1-8 \delta) / 2 \sqrt{2}$; (iii) three neighbours at a distance $a(1+8 \delta) / 2 \sqrt{2}$. The diffusion jump of an oxygen ion to a vacant site of type (ii) involves separating two neighbouring octahedral cations and is thus unlikely. For routes involving unoccupied sites of types (i) and (iii) the activation energies calculated using the model of Glyde are 2.58 and $3.08 \mathrm{eV}$ respectively. These considerations suggest that in the temperature range of measurement the most mobile ionic species is $\mathrm{Mg}^{2+}$ and it migrates via a tetrahedral-octahedral-tetrahedral route.

The activation energy for conduction in the intrinsic region can be represented as $Q=Q_{f}+Q_{m}$, where $Q_{f}$ is the energy required for the vacancy formation and $Q_{m}$ the energy for vacancy migration. By extending the analogy between face-centred cubic metals and cubic spinels $Q_{f}$ and $Q_{m}$ can be evaluated using the expressions (Glyde 1967):

$$
\begin{aligned}
& Q_{f}=1.17 \times 10^{-2}(k / h)^{2} m \theta_{\mathrm{D}}^{2} \mathrm{~d}^{2}, \\
& Q_{m}=1.04 \times 10^{-2}(k / h)^{2} m \theta_{\mathrm{D}}^{2} \mathrm{~d}^{2} .
\end{aligned}
$$

These relations give $Q_{f}=0.86 \mathrm{eV}$ and $Q_{m}=0.76 \mathrm{eV}$ for $\mathrm{MgAl}_{2} \mathrm{O}_{4}$. Unfortunately independent values are not available for comparison. In the analysis of Glyde (1967) the relation between $Q_{m}$ and $\theta_{\mathrm{D}}$ follows directly from the Debye model and dynamic theories of diffusion. The relation between $Q_{f}$ and $\theta_{\mathrm{D}}$ is based on the law of corresponding states.

\section{Acknowledgement}

The authors are grateful to Ms Thelma Pinto and Mr A V Narayan for assistance in the preparation of the manuscript. 


\section{References}

Bacon G E 1952 Acta Crystallogr. 5684

Darken L S and Gurry R W 1945 J. Am. Chem. Soc. 671398

Glyde H R 1967 J. Phys. Chem. Solids 282061

Hodgman C D (ed.) 1963 Handbook of chemistry and physics (44th edn) (Ohio, USA: The Chemical Rubber Publishing Co)

Metselaar R and Hoefsloot A M 1987 Solid State Ionics 24305

Schmalzried H 1974 Solid state reactions (Wein heim, Germany: Verlag Chemie) 